\title{
CLINICOPATHOLOGICAL STUDY OF TUMOURS OF HYPOPHARYNX
}

\author{
Rajesh Kumar Sadangi ${ }^{1}$, Santosh Kumar Misra ${ }^{2}$
}

${ }_{1}^{1}$ Associate Consultant, Department of ENT, Vikash Multispeciality Hospital, Bargarh, Odisha. 2 Professor and HOD, Department of ENT, MKCG. Medical College, Berhampur, Odisha.

\begin{tabular}{l}
\hline ABSTRACT \\
BACKGROUND \\
Hypopharyngeal tumours are increasing rapidly and its prognosis is not very good. The study is intended to find out the common \\
clinical presentation and risk factors so that prevention and early diagnosis will be possible.
\end{tabular}

\section{MATERIALS AND METHODS}

This study was carried out in the Department of Otorhinolaryngology, MKCG Medical College Hospital, Berhampur, Odisha from 2011 to 2013. The study was conducted by thorough history, clinical evaluation, FNAC of lymph node, histopathological study of biopsy from tumour, relevant laboratory investigations as required, chest X-ray and soft tissue neck.

\section{RESULTS}

Clinicopathological study of 42 cases of tumour of hypopharynx in Department of ENT, MKCG Medical College, Berhampur done in a period of two years. $15.7 \%$ of hypopharyngeal tumours seen out of total head and neck tumours. Peak age group was seen from $5^{\text {th }}$ to $7^{\text {th }}$ decades, males were affected more than females (29:13), chewing tobacco was the most common risk factor followed by smoking and alcohol. Dysphagia, neck swelling and otalgia were commonest symptoms. Pyriform fossa involvement was seen most commonly. Lymph node metastases were seen in $57.1 \%$ of cases. Most cases presented in advanced stages with all cases found histologically were of squamous cell carcinoma.

\section{CONCLUSION}

Delayed presentation is a major problem in hypopharyngeal tumours leading to multiple sites of involvement and making the prognosis poorer. Chewing tobacco is an important aetiological factor along with smoking and alcohol for the development of hypopharyngeal tumours. Early diagnosis is possible by thorough examination of patients with symptoms of dysphagia and cervical lymphadenopathy.

\section{KEYWORDS}

Hypopharyngeal Tumours, Chewing Tobacco, Dysphagia, Lymphadenopathy, Pyriform Fossa, Postcricoid, Posterior Pharyngeal Wall.

HOW TO CITE THIS ARTICLE: Sadangi RK, Misra SK. Clinicopathological study of tumours of hypopharynx. J. Evolution Med. Dent. Sci. 2017;6(93):6744-6746, DOI: 10.14260/jemds/2017/1460

\section{BACKGROUND}

Hypopharynx is the part of pharynx which is placed behind and partly on the sides of the larynx. It extends superiorly at the level of plane of body of hyoid bone to the post pharyngeal to inferiorly at the level of lower border of cricoids. It is a highly important anatomical site since physiologically it is a component of the upper aerodigestive tract and, in its upper part, it represents a common passage for both respiration and deglutition. Hypopharyngeal tumours have constituently been one third as common as laryngeal tumours.

Hypopharyngeal tumours appear commonly in $4^{\text {th }}$ to $6^{\text {th }}$ decade( 1,2$)$ and extremely rare in children.(3) Males are affected more than females in hypopharyngeal tumours with female predominance in postcricoid tumours.

Excessive alcohol and tobacco use are the primary risk factors for hypopharyngeal cancer.(4,5)

'Financial or Other Competing Interest': None.

Submission 18-03-2017, Peer Review 20-11-2017,

Acceptance 27-11-2017, Published 11-12-2017.

Corresponding Author:

Dr. Rajesh Kumar Sadangi,

AT/PO-Khandahata

Via- Tora Dist. Bargarh-768040,

Odisha, India.

E-mail: rsarangi57@gmail.com

DOI: $10.14260 /$ jemds $/ 2017 / 1460$
Plummer-Vinson syndrome is a premalignant condition for development of postcricoid cancers. Pyriform fossa tumours are most common among hypopharyngeal tumours followed by postcricoid and posterior pharyngeal wall tumours.

Cervical lymph node metastasis is very common in hypopharyngeal tumours and most of the patients present in advanced stage with dysphagia as common symptom. Benign tumours are rare in hypopharynx and most of the malignant tumours are squamous cell carcinomas.

Though hypopharynx and larynx are only millimetres apart, their natural history is much different. Hypopharyngeal cancer is associated with less than half survival rate than of its laryngeal neighbour. So early diagnosis of hypopharyngeal involvement is important for better management. Again no factor or gene studied is as good as standard clinicopathological staging at predicting a cure for the patient. It is therefore important to study the clinicopathological aspect of tumours of hypopharynx which this study intends to analyse.

\section{MATERIALS AND METHODS}

This study was carried out in the Department of Otorhinolaryngology, MKCG Medical College Hospital, Berhampur, Odisha from 2011 to 2013. Inclusion criteria - All the patients presenting with symptoms suspected to be due to tumours of hypopharynx. 
Exclusion Criteria- Noncompliant patients.

\section{Data Recorded}

- Thorough history.

- Clinical evaluation.

- FNAC of lymph node.

- Histopathological study of biopsy from tumour.

- Relevant laboratory investigations as required.

- Chest X-ray and soft tissue neck.

\section{RESULTS}

Amongst 374 Head and Neck tumours, 42 cases were detected as tumours of hypopharynx with an incidence of $11.2 \%$ in our institution. Most of the patients were of $4^{\text {th }}$ to $6^{\text {th }}$ decade of life. Male to female involvement is 29: 13. Most of the persons are from middle and low socioeconomic class. Chewing tobacco is the most common (59.5\%) risk factor for hypopharyngeal tumours followed by smoking (38.09\%) and alcohol (19.04\%). 78.5\% patients present with dysphagia followed by neck swelling (45.2\%) and otalgia (33.3\%). Pyriform fossa tumours are commonest with $54.7 \%$, followed by postcricoid $21.4 \%$ and posterior pharyngeal wall $9.5 \%$. Multiple sites of involvement in hypopharynx is seen in $14.2 \%$ of cases. $57.1 \%$ of hypopharyngeal tumours had lymphadenopathy at presentation. Postcricoid tumours with $33.3 \%$ had least lymphatic metastasis at presentation. Metastatic involvement of Level III (62.5\%) and II (37.5\%) cervical lymph nodes were most common. Bilateral involvement was seen in $16.6 \%$ of cases. N1 staging of lymph nodes were commonest with $33.33 \%$ in hypopharyngeal tumours. All the tumours were malignant and were squamous cell carcinoma histologically.

\begin{tabular}{|c|c|c|c|c|c|}
\hline & 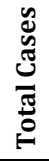 & $\begin{array}{l}\overline{0} \\
\frac{0}{0} \\
\frac{8}{4}\end{array}$ & 足 & 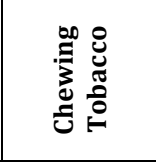 & ڤ્ \\
\hline $\begin{array}{l}\text { Pyriform } \\
\text { fossa }\end{array}$ & 23 & $2(8.69 \%)$ & $11(47.8 \%)$ & $14(60.8 \%)$ & $3(13.4 \%)$ \\
\hline Postcricoid & 9 & $2(22.2 \%)$ & $1(11.1 \%)$ & $5(55.5 \%)$ & $3(33.3 \%)$ \\
\hline $\begin{array}{c}\text { Posterior } \\
\text { pharyngeal } \\
\text { wall }\end{array}$ & 4 & $3(75 \%)$ & $3(75 \%)$ & $2(50 \%)$ & 0 \\
\hline $\begin{array}{c}\text { Multiple } \\
\text { sites } \\
\text { involvement }\end{array}$ & 6 & $1(16.6 \%)$ & $1(11.1 \%)$ & $4(66.6 \%)$ & $1(16.6 \%)$ \\
\hline Total & 42 & $8(19.4 \%)$ & $16(38.09 \%)$ & $25(59.5 \%)$ & $7(16.66 \%)$ \\
\hline \multicolumn{6}{|c|}{ Habit } \\
\hline
\end{tabular}

\begin{tabular}{|c|c|c|}
\hline Symptoms & No. of Cases & \% \\
\hline Dysphagia & 33 & 78.5 \\
\hline Neck swelling & 19 & 45.2 \\
\hline Otalgia & 14 & 33.3 \\
\hline Voice change & 13 & 30.9 \\
\hline Throat pain & 11 & 26.1 \\
\hline F. B. Sensation & 3 & 7.1 \\
\hline $\begin{array}{c}\text { Respiratory } \\
\text { Distress }\end{array}$ & 2 & 4.7 \\
\hline \multicolumn{3}{|c|}{ Clinical Presentation } \\
\hline
\end{tabular}

\begin{tabular}{|c|c|c|c|c|}
\hline & $\begin{array}{c}\text { Pyriform } \\
\text { Fossa }\end{array}$ & $\begin{array}{c}\text { Post } \\
\text { Cricoid }\end{array}$ & $\begin{array}{c}\text { Posterior } \\
\text { pharyngeal } \\
\text { Wall }\end{array}$ & $\begin{array}{c}\text { Multiple } \\
\text { Sites } \\
\text { Involvement }\end{array}$ \\
\hline Total (42) & $23(54.7 \%)$ & $\begin{array}{c}9 \\
(21.4 \%)\end{array}$ & $4(9.5 \%)$ & $6(14.2 \%)$ \\
\hline Male (29) & 18 & 3 & 4 & 4 \\
\hline Female (13) & 5 & 6 & 0 & 2 \\
\hline
\end{tabular}

\begin{tabular}{|c|c|c|}
\hline \multicolumn{3}{|c|}{ Subsites of Hypopharynx Involved } \\
\hline & $\begin{array}{l}\text { No. of } \\
\text { Cases }\end{array}$ & $\begin{array}{c}\text { No. of Cases With } \\
\text { Lymphadenopathy at } \\
\text { Presentation }\end{array}$ \\
\hline All Cases & 42 & $24(57.1 \%)$ \\
\hline Pyriform Fossa & 23 & $14(60.8 \%)$ \\
\hline Post. Cricoid & 9 & $3(33.3 \%)$ \\
\hline $\begin{array}{c}\text { Posterior pharyngeal } \\
\text { Wall }\end{array}$ & 4 & $2(50 \%)$ \\
\hline Multiple Sites & 6 & $5(83.3 \%)$ \\
\hline \multicolumn{3}{|c|}{ Lymph Node Involvement } \\
\hline
\end{tabular}

\begin{tabular}{|c|c|c|c|c|}
\hline & N0 & N1 & N2 & N3 \\
\hline Total & $18(42.85 \%)$ & $14(33.33 \%)$ & $10(23.8 \%)$ & 0 \\
\hline PF & 9 & 8 & 6 & 0 \\
\hline PC & 6 & 3 & 0 & 0 \\
\hline PPW & 2 & 2 & 0 & 0 \\
\hline Multiple Sites & 1 & 1 & 4 & 0 \\
\hline \multicolumn{4}{|c|}{ Lymph Node Staging } \\
\hline
\end{tabular}

\begin{tabular}{|c|c|c|}
\hline \multirow{2}{*}{ Total } & \multirow{2}{*}{ Benign } & Malignant \\
\cline { 3 - 3 } & & (Squamous Cell Carcinoma) \\
\hline 42 & 0 & $42(100 \%)$ \\
\hline \multicolumn{3}{|c|}{ Histopathological Types } \\
\hline
\end{tabular}

\section{DISCUSSION}

The total number of patients presented in the Department of Otolaryngology, MKCG Medical College Hospital, Berhampur between the period 2011 and 2013 were 71700, out of which 374 cases were Head and Neck tumours. This is almost $0.5 \%$ of all the cases attending to the Department for various ENT problems. Amongst 374 Head and Neck tumours, 42 cases were detected as tumours of hypopharynx. So, the incidence of hypopharyngeal tumours in our institution is 42 of $374=$ $11.2 \%$.

In my study, peak incidence of the tumours are seen in $6^{\text {th }}$ decade i.e. $33.3 \%$ and maximum number of cases $(71.4 \%)$ were in $5^{\text {th }}$ to $7^{\text {th }}$ decade. This finding is similar to the previous studies of Chandrashekhar (1965) where $50 \%$ of cases were in $6^{\text {th }}$ decade and Sanjeev Bhagat et al (2001) where maximum no. of cases were in $4^{\text {th }}$ to $7^{\text {th }}$ decade.(2)

Hypopharyngeal tumours are seen more in male with male to female ratio 2.23:1. For pyriform fossa tumours it is 3.6: 1 , but for postcricoid tumours it is 1: 2 . My finding is nearly similar to that of Maran Verma et al in 1990 found that male to female ratio was 7:1 and in 1992 Sharma and Chhangani found it 10:1.(6)

So my study indicates that the incidence of hypopharyngeal tumours are increasing among females which may be due to increase in the use of tobacco in females.

In my study, hypopharyngeal tumours were seen more commonly in persons of low socioeconomic class. This may be due to nutritional deficiencies of iron and vitamins in these persons.

Deka (1975) in his study reported smoking as most common (70\%) risk factor followed by alcohol (35\%) and pan and betel nut (20\%).(7) Sanjeev et al observed that poor oral hygiene (43.3\%), smoking (40\%) and alcohol (50\%) were important predisposing factors.(2)

In my study, habit of chewing tobacco is seen in $59.5 \%$ of cases and is the most common risk factor for hypopharyngeal tumours followed by smoking (38.09\%) and alcohol (19.04\%). Habit of tobacco chewing is very common in this 
locality which may be the reason of it being commonest risk factor.

Dysphagia (78.5\%), neck swelling (45.2\%), otalgia (33.3\%) are commonest symptoms found in my study. Altered voice is seen in $30.9 \%$ cases. This finding is consistent with the findings of Hoffman et al (1997) ${ }^{(8)}$ and Sanjeev et al (2001).(2)

In my study, pyriform fossa is the commonest site with $54.7 \%$ involvement. Postcricoid tumours are seen in $21.4 \%$ and posterior pharyngeal wall in $9.5 \%$ of cases. Involvement of multiple subsites are seen in $14.2 \%$ of cases.

This is similar to studies of Chandrashekhar (1965), Shukla et al (1995), Kurtulmax et al (1997) and Sanjeev et al (2001). Findings of my study do not coincide with Harrison (1970) and Verma et al (1990); they reported postcricoid tumours as commonest and incidence was $59.7 \%$ and $45.9 \%$ followed by pyriform fossa in $34.3 \%$ and $29.8 \%$ of cases and posterior pharyngeal wall in $5.9 \%$ and $24.8 \%$ of cases.

Multiple sites of involvement are seen commonly which may be due to delay in presentation and diagnosis.

Metastatic cervical lymphadenopathy is $57.1 \%$ in my study with $60.8 \%, 33.3 \%, 50 \%$ and $83.3 \%$ in pyriform fossa, postcricoid, posterior pharyngeal wall and multiple sites involvement respectively. Most common lymph node involved are Level III (62.5\%) and Level II (37.5\%). Bilateral involvement is seen in $16.6 \%$ of hypopharyngeal tumours.

According to Stell and Swift in 1987, lymph node metastasis was seen in $65 \%, 30 \%$, and $40 \%$ in pyriform fossa, postcricoid and posterior pharyngeal wall respectively. Sanjeev et al found overall cervical lymph node metastasis in $60 \%$ of cases, with $66.6 \%, 25 \%$ and $50 \%$ in pyriform fossa, postcricoid and posterior pharyngeal wall respectively.(2)

Lymphatic metastasis is highest in pyriform fossa tumours and least in postcricoid tumours. This could be explained due to rich lymphatic drainage seen in pyriform fossa and least in postcricoid region.

Nodal stage is important in determining the survival in hypopharyngeal tumours. In my study, N0 is seen in $42.85 \%$, $\mathrm{N} 133.33 \%$ and $\mathrm{N} 223.8 \%$ of cases. My result is similar to Hahn et al (1987), noted N0 43\%, N1 25\%, N2 17\% and N3 $14 \%$ and Sanjeev et al (2001) noted N0 40\%, N1 40\%, N2 $16.6 \%$ and N3 3.3\%

All cases in my study were squamous cell carcinoma which coincide with the study of Barua et al (1993) where majority of tumours of hypopharynx were squamous cell carcinoma. In the study of Sanjeev et al, (2001) 100\% were histologically squamous cell carcinoma.

In my study, 50\% tumours were moderately differentiated and $30.9 \%$ poorly differentiated, which coincide with the study of Sanjeev et al in 2001.

\section{CONCLUSION}

- Though the incidence of hypopharyngeal tumours are low, considering its prognosis, it is a major health problem.

- Hypopharyngeal tumours are increasing among females; may be due to increased use of tobacco mostly in chewing form. So awareness about tobacco use and alcohol is an important aspect of prevention of these tumours.

- Multiple sites of involvement are seen frequently due to delay in presentation and diagnosis.

- All cases of cervical lymphadenopathy, especially in elderly persons should have high suspicion of hypopharyngeal tumours and thorough examination should be done.

- $\quad$ Specific health education leading to early reporting of the disease by the patients and high clinical suspicion and proper referral by the healthcare providers will lead to early detection of hypopharyngeal tumours that will decrease the patients with advanced tumour.

\section{REFERENCES}

[1] Uzcudun AE, Bravo Fernández P, Sánchez JJ, et al. Clinical features of pharyngeal cancer: a retrospective study of 258 consecutive patients. J Laryngol Otol 2001;115(2):112-8.

[2] Bhagat S, Singh B, Verma SK, et al. Clinicopathological study of tumours of hypopharynx. Indian Journal of Otolarytgol Head \& Neck Surg 2003;55(4):241-3.

[3] Siddiqui F, Sarin R, Agarwal JP, et al. Squamous carcinoma of the larynx and hypopharynx in children: a distinct clinical entity? Med Pediatr Oncol 2003;40(5):322-4.

[4] Blot WJ, McLaughlin JK, Winn DM, et al. Smoking and drinking in relation to oral and pharyngeal cancer. Cancer Res 1988;48(11):3282-7.

[5] Day GL, Blot WJ, Shore RE, et al. Second cancers following oral and pharyngeal cancers: role of tobacco and alcohol. J Natl Cancer Inst 1994;86(2):131-7.

[6] Sharma M, Changani DL. Malignancy of larynx and laryngopharynx. Indian Journal of Otolaryngology and Head and Neck Surgery 1992;1(2):93-5.

[7] Deka RC. Clinical and whole organ serial section studies on cancer of larynx and laryngopharynx. Indian Journal of otolaryngology 1975;27(1):7-25.

[8] Hoffman HT, Karnell LH, Shah JP, et al. Hypopharyngeal cancer patient care evaluation. Laryngoscope 1997;107(8):1005-17. 